\title{
Patient-identified early clinical warning signs of nodular melanoma: a qualitative study
}

\author{
Adina Coroiu ${ }^{1 *}$, Chelsea Moran², Jessica A. Davine ${ }^{1}$, Kyla Brophy ${ }^{3}$, Catherine Bergeron ${ }^{3}$, Hensin Tsao ${ }^{4,5}$, \\ Annett Körner ${ }^{3}$, Susan M. Swetter ${ }^{6,7 \dagger}$ and Alan C. Geller ${ }^{1 \dagger}$
}

\begin{abstract}
Background: Nodular (NM) and superficial spreading melanoma (SSM) show different disease trajectories, with more rapid development in NM and fewer opportunities for early detection often resulting in worse outcomes. Our study described the patient-identified early signs of thin NM via comparisons to thin ( $\leq 2 \mathrm{~mm}$ ) SSM and thick (> 2 $\mathrm{mm}) \mathrm{NM}$.

Methods: We conducted semi-structured interviews with NM and SSM patients and analyzed the data using thematic analysis.

Results: We enrolled 34 NM and 32 SSM patients. Melanoma early signs uniquely identified by patients with thin NM included white, blue or black coloration, "dot-like" size, fast changes in shape and color observed over 2 weeks, elevation and texture or "puffiness" over 6-12 months, and the sensation that the mole "did not feel right". Early signs reported by both thin NM and thin SSM patients included round or oblong shape, "jagged" border, pink/red, brown/reddish or dark coloration, "elevated like a pimple" or "tiny bump", fast color darkening, diameter growth, and border irregularity, and mole feeling "really itchy".
\end{abstract}

Conclusions: We found evidence that early signs of NM can be self-identified, which has important implications for the earlier detection of this most aggressive type of melanoma by both health professionals and patients.

Keywords: Nodular melanoma, Superficial spreading melanoma, Patient-identified early signs, Semi-structured interviews, Thematic analysis

\section{Introduction}

Melanoma is the most common fatal type of skin cancer, and its incidence continues to rise [1,2]. In the United States melanoma incidence increased from 20.7 per 100, 000 in 2001 to 28.2 per 100,000 in 2015 [3]. Superficial spreading melanoma (SSM) and nodular melanoma (NM) are the most frequent subtypes, accounting for

\footnotetext{
* Correspondence: acoroiu@hsph.harvard.edu

${ }^{+}$Authors Susan M. Swetter and Alan C. Geller shared senior authorship.

'Department of Social and Behavioral Sciences, Harvard T.H. Chan School of Public Health, 401 Park Drive, West Wing 4th floor, 403G, Boston, MA 02215, USA

Full list of author information is available at the end of the article
}

$80 \%$ of all diagnoses of cutaneous melanoma (CM) [4]. Newer histopathologic classifications of CM define these subtypes as occurring on skin without high cumulative sun damage (CSD), i.e., low-CSD melanoma, and SSM and NM are more likely to harbor the BRAF V600 mutation compared to other melanoma subtypes [5].

Tumour thickness at diagnosis is the key predictor of survival for CM, [6-8] and NM is usually thicker at diagnosis compared to SSM (median thickness at diagnosis: $2.19-2.6 \mathrm{~mm}$ for $\mathrm{NM}$ versus $0.54-0.6 \mathrm{~mm}$ for SSM) $[9,10]$. While $90 \%$ of SSMs are diagnosed as thin tumours $(<=2 \mathrm{~mm}$; T1/T2) only $20 \%$ of NMs are [10],

(c) The Author(s). 2021 Open Access This article is licensed under a Creative Commons Attribution 4.0 International License, which permits use, sharing, adaptation, distribution and reproduction in any medium or format, as long as you give appropriate credit to the original author(s) and the source, provide a link to the Creative Commons licence, and indicate if changes were made. The images or other third party material in this article are included in the article's Creative Commons licence, unless indicated otherwise in a credit line to the material. If material is not included in the article's Creative Commons licence and your intended use is not permitted by statutory regulation or exceeds the permitted use, you will need to obtain permission directly from the copyright holder. To view a copy of this licence, visit http://creativecommons.org/licenses/by/4.0/ The Creative Commons Public Domain Dedication waiver (http://creativecommons.org/publicdomain/zero/1.0/) applies to the data made available in this article, unless otherwise stated in a credit line to the data. 
with more than half (56\%) of NMs diagnosed at a thicker stage $(>2 \mathrm{~mm}, \mathrm{~T} 3 / \mathrm{T} 4)$ [9]. Likewise, SSM accounts for $56 \%$ of invasive $\mathrm{CM}$ diagnoses and $30 \%$ of all deaths compared to NM, which accounts for only $14 \%$ of invasive diagnoses but $43 \%$ of all CM deaths [10]. Prognosis for thin NM is poorer compared to thin SSM [11], with reported rates for disease-free survival ranging from 82 to $84.9 \%$ for thin NM versus $91-96.4 \%$ for thin SSM [12, 13], although other studies show similar prognosis when matched for clinicopathologic factors.

Currently, it is unclear whether the increased thickness at diagnosis in NM can be attributed to sex- or agebased differences, e.g., NM tends to be diagnosed more often in males and in individuals 50 years of age and older $[12,14,15]$; potential delays in diagnosis due to atypical clinical presentation that does not fit general criteria for the early identification of problematic skin lesions $[16,17]$ e.g., the $\mathrm{ABCDE}$ rule -asymmetry, border irregularity, uneven color, large diameter $(>6 \mathrm{~mm})$ and evolution [18-20] or the EFG rule -elevated, firm, and growing lesions $[21,22]$; or whether NM is a biologically distinct, more aggressive subtype of melanoma that grows and spreads faster than other CM subtypes [4, $12,23]$. What is currently known is that NM tends to elude early clinical detection, with only a minority being detected early (T1/T2 stage) by dermatologists and most being identified later (T3/T4 stage) when melanoma may have already spread to regional lymph nodes [9]. Importantly, more NMs (44\%) compared to SSMs (38\%) are self-detected or first identified by family or friends as opposed to healthcare professionals $[24,25]$. While physician-detected melanomas tend to be thinner compared to patient-detected lesions most melanoma are self-detected: by patients, spouses or friends $[15,26]$. These data suggest a critical window of opportunity for early detection, in which patient perspectives can promote understanding of the early clinical signs of NM.

The few studies that have investigated early warning signs of NM versus SSM almost exclusively used quantitative methods either for data collection and/or data analysis (key findings summarized in the Additional file 1). As a result, detail about patient-recognized clinical features is limited to questions posed in descriptive, close-ended surveys or the availability of medical records data. Qualitative methods are patient-centered by design and are best suited to investigate patient perspectives on early signs and symptoms of medical conditions, such as melanoma, which develops with visible, pre-clinical signs [19]. Semi-structured interviews can explore patient narratives about early detection in greater depth, including key identifiable features, the circumstances that led to the identification of problematic lesions, and the patient's knowledge base of the condition prior to detection. In addition, the use of prompts and guided questioning can improve patient recall [27].

\section{Research objective}

To investigate more thoroughly the early signs of NM from the patient perspective, we conducted a qualitative study with semi-structured interviews focused on producing critical knowledge about mole appearance, observed changes in mole features over time, and sensations experienced about the problematic mole/lesion, as they became apparent to patients in the 12 months prior to diagnostic CM biopsy. This timeline for recall is common in melanoma prevention research and has been previously used to collect data on history of sunburns, sun exposure and practice of skin self-examination [2832]. As per previous reports, a thickness cut-off of $2 \mathrm{~mm}$ was used to differentiate between thinner melanoma ( $\leq$ $2 \mathrm{~mm}, \mathrm{~T} 1 / \mathrm{T} 2)$ and thicker melanoma (> $2 \mathrm{~mm}, \mathrm{~T} 3 / \mathrm{T} 4)$. More specifically, we describe the patient-identified early signs of NM via comparisons to thin $(\leq 2 \mathrm{~mm}) \mathrm{SSM}$ and thick (>2 mm) NM.

\section{Materials and methods Study design}

The study employed a qualitative design with semistructured interviews. Semi-structured interviews aim to explore individual viewpoints and the meaning behind people's experiences to give a glimpse into the lived experiences as they occurred prior to theoretical explanations [33]. Individual interviews were conducted to collect patient-driven data addressing the main research questions. The goal was to develop a nuanced and comprehensive understanding of the clinical features of the problematic mole (or lesion) that participants identified on their own prior to receiving a diagnosis of melanoma. Study findings are reported as per the Standards for Reporting Qualitative Research (SRQR) [34]. The 21item SRQR checklist is included as Supplementary Material.

\section{Participants and procedures}

The study was approved by the Institutional Research Board (IRB) of Harvard T.H. Chan School of Public Health and the Research Ethics Board (REB) of McGill University, which are in agreement with the Declaration of Helsinki. Eligibility for the study included a confirmed diagnosis of either NM or SSM and receiving treatment at the Masachussets General Hospital between 2012 and 2017. Eligible participants were identified through medical hospital records and included men and women diagnosed with thin $(\leq 2 \mathrm{~mm})$ and thick $(>2 \mathrm{~mm}) \mathrm{NM}$ and SSM. We identified all eligible NM patients $(n=109)$ and matched their profiles by sex, age at diagnosis, and melanoma thickness to SSM patients (1 NM to 3 SSM). 
The SSM matching pool was chosen randomly from a larger participant pool, as the MGH had disproportionate larger patient samples of SSM compared to NM, as is typical for these melanoma subtypes. Active enrollment occurred between December 2017 and April 2018. The flowchart of participation is included in Fig. 1.

Eligible participants received a letter via mail signed by their MGH treating physician informing them about the study and offering an opportunity to opt out of further communication about the study. Subsequently, eligible participants who had not opted out after the initial letter received a study package via mail, which included a brief study description, consent forms, and a brief demographic survey. The cover letter explicitly offered another chance to opt out of further study communication. Participants who had not opted out at this stage, were contacted via phone to discuss enrollment. All participants provided written informed consent prior to enrollment in the study. We planned to recruit approximately
80 patients (40 NM and $40 \mathrm{SSM}$ ) and continued scheduling interviews until we exhausted our sample of consenting participants. We reached out to patients five times before determining that they were inactive.

\section{Data sources}

Data were collected via a brief sociodemographic survey and semi-structured interviews. The survey items inquired about key demographic characteristics (education level, age), and health behaviours and attitudes about melanoma prevention and early detection, and were administred solely to provide more context about the recruited sample and to help with contextualizing the qualitative findings. The interview guide (Additional file 1) included questions about the appearance of melanoma when initially spotted using prompts that were guided by the ABCDE criteria [18-20] which identifies problematic lesions by Asymmetry, irregular Borders, varying shades and Colors inside 1 mole, large Diameter

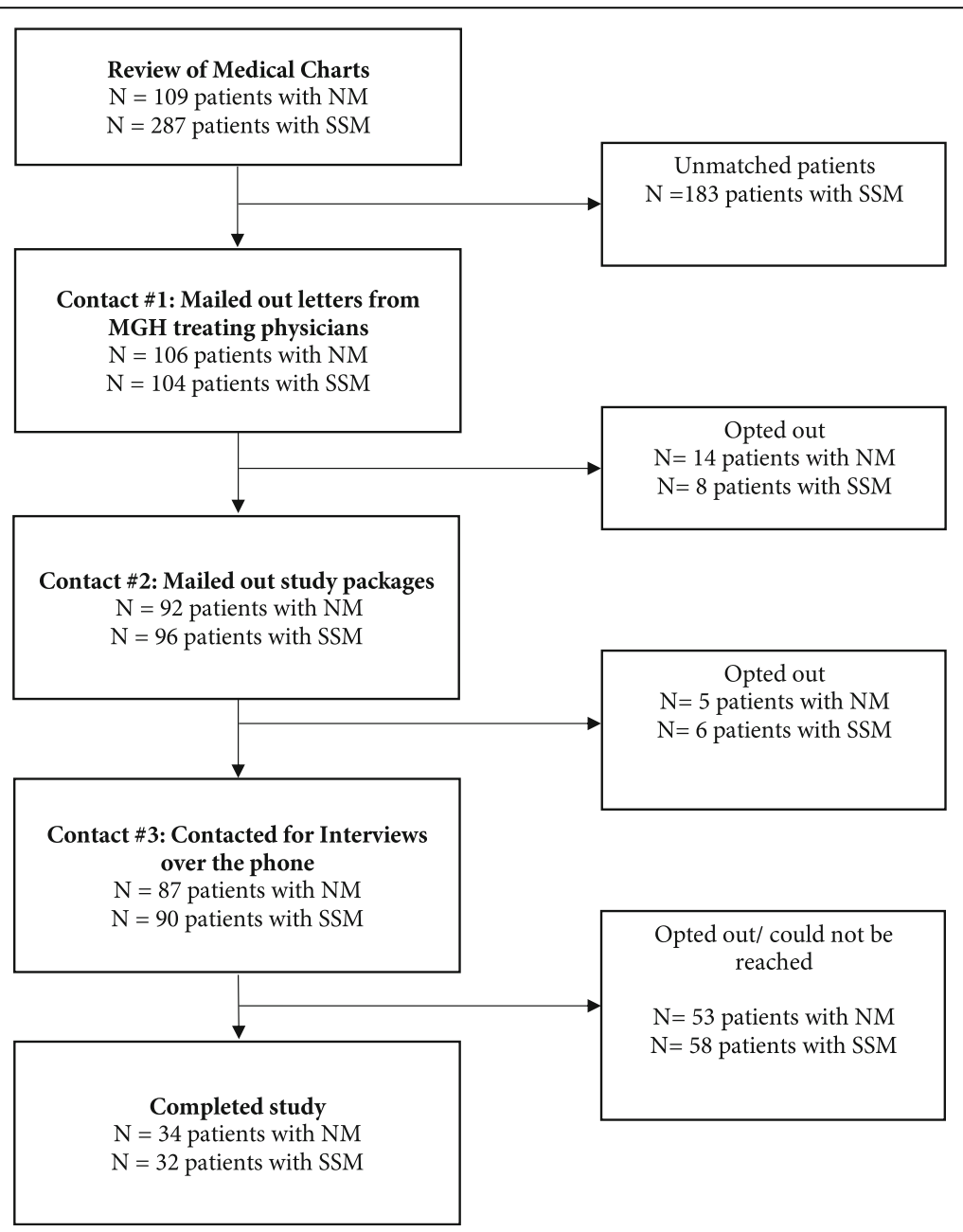

Fig. 1 Study flowchart detailing study selection, enrollment, and completion. Legend. NM = nodular melanoma; SSM = superficial spreading melanoma; MGH = Masachussetts General Hospital 
(>6 mm), and Evolution or changes in any of these criteria. We specifically asked about physical sensations experienced in or around the mole. The time of reference for reporting mole features and changes was 12 months prior to diagnosis. The same set of questions was posed to each participant, with prompts to facilitate recall, which allowed for flexibility to follow up on potentially relevant material. The interviews were conducted over the phone $(\mathrm{CM})$, lasted between 20 and $40 \mathrm{~min}$, were audio-recorded using open access software (Open Broadcaster Software), and were transcribed verbatim by a professional transcription service.

\section{Data analysis}

Verbatim transcriptions of the interviews were imported into Dedoose [35], a type of software used for qualitative analyses. We used thematic analysis [36] and coded the interview data using an inductive-deductive method whereby a coding manual was created based on the review of the first 10 interviews (deductive approach), which was updated throughout the coding process, as new codes emerged (inductive approach). The initial round of coding was split among three coders (CB, CM, $\mathrm{KB})$. The second round of coding was conducted by another coder (AC). Themes were generated and refined in an iterative fashion throughout multiple team meetings (AC, CM, JD, AG) held between September and December 2019. To ensure the trustworthiness and reproducibility of our findings [37], we used two criteria: credibility where the team reviewed the codes carefully in an iterative fashion and agreed on a final set of codes; and confirmability, where we challenged our own biases by practicing self-awareness throughout the coding process and by challenging personal assumptions during team discussions in which we collaboratively interpreted the data.

\section{Data synthesis}

Data are presented in tabular format. Qualitative findings were summarized according to the established ABCDE criteria [18-20] and also incorporated discrete categories of data described by participants, including a) mole elevation (thickness or depth), b) perceived changes in any of the mole features and the chronology for observed changes; and c) clinical signs and symptoms experienced in or around the problematic mole. In line with the study aims, we used the thin NM group as our reference for contrasts with thin SSM and thick NM groups.

\section{Results}

\section{Sample characteristics}

The study sample comprised 66 patients: 34 patients diagnosed with NM (thin, $n=16$; thick, $n=18$ ) and 32 patients diagnosed with SSM (thin, $n=23$; thick, $n=9$ ) (see Table 1). Mean time elapsed from diagnosis to interview for the entire sample was 2.56 years (Mean $\mathrm{NM}_{\mathrm{N}}=2.52$; Median ${ }_{\mathrm{NM}}=2.26$; Mean $\mathrm{SSM}=2.42$, Median $\mathrm{SSM}=2.71)$. Patients with thin NM had the lowest mean age at diagnosis (56 versus 59,61, 63). Across all four tumour thickness groups, most patients $(>50 \%)$ completed college. In addition, the majority of patients $(n=$ 56 ; $85 \%)$ were diagnosed with their first melanoma; among patients diagnosed with a second melanoma $(n=$ 10), 6 were NMs and 4 were SSMs. Self-reported rates for self-checking for melanoma in the 12 months prior to diagnosis ranged from 56\% (thick SSM and thick NM) to $75 \%$ (thin NM). Self-reported rates for receiving a medical skin exam in the 12 months prior to diagnosis ranged from 22\% (thick SSM) to 65\% (thin SSM).

Patients with thin NM reported fewer physical symptoms experienced in the 12 months prior to diagnosis, such as itching, bleeding, irritation, or pain compared to patients with thin and thick SSM or thick NM. Further, there were no reports of tenderness of the mole, discharge or peeling among thin NMs. Half of patients with thin NM self-discovered their melanoma compared to approximately $40 \%$ of thin SSM and $>75 \%$ of thick NM and thick SSM. Approximately half of patients with thin NM reported some confidence ("somewhat", "quite", or "extremely" confident) in identifying problematic moles compared to $1 / 3$ of patients with thick NMs and thick SSM and $1 / 4$ of thin SSM's. More than 3/4 patients from each group self-identified as "generally paying attention to their health". Descriptive statistics are included in Table 2.

A summary of qualitative findings pertaining to the self-identified early signs of melanoma is included in Table 3. For brevity purposes, the thick SSM group ( $n=$ 9) was not included in the qualitative analysis, as it offered no new information beyond what was already provided by the other two comparison groups, thin SSM and thick NM.

\section{Self-identified early signs of melanoma that are unique to nodular melanoma}

With respect to mole appearance, thin NM's stood out in terms of coloration, e.g., "white", "blueish dark"," blueish, multi-colored", or "black", and diameter, e.g., "tiny, tiny, little spot" or "little white dot". In addition, thin NM's reported fast changes in shape, e.g., from "round" to "oblong"; fast changes in color, e.g., from" brownish" to "darker with brown tinges" or from "brown" to "black, in a dripping pattern"; and developed vertical growth over the period of 2 weeks. Other changes unique to thin NM, which reportedly occurred over the course of several months to 1 year, included changes in color, e.g., 
Table 1 Sample characteristics

\begin{tabular}{|c|c|c|c|c|}
\hline \multirow[t]{2}{*}{ Variable, \% (n) } & \multicolumn{2}{|c|}{ Nodular Melanoma } & \multicolumn{2}{|c|}{ Superficial Spreading Melanoma } \\
\hline & $\leq 2 \mathrm{~mm}(n=16)$ & $>2 \mathrm{~mm}(n=18)$ & $\leq 2 \mathrm{~mm}(n=23)$ & $>2 \mathrm{~mm}(n=9)$ \\
\hline Sex, Female & $62.5(10)$ & $22.2(4)$ & $52.2(12)$ & $22.2(2)$ \\
\hline Age at diagnosis, M (SD), Range & $56.4(14.3), 24-81$ & $63.0(11.4), 44-86$ & $60.7(17.7), 26-92$ & $58.8(7.5), 45-71$ \\
\hline $20-40$ & $12.5(2)$ & $0.0(0)$ & $17.4(4)$ & $0.0(0)$ \\
\hline $41-60$ & $43.7(7)$ & $44.4(8)$ & $26.1(6)$ & $66.7(6)$ \\
\hline $61-80$ & $37.5(6)$ & $44.4(8)$ & $47.8(11)$ & $33.3(3)$ \\
\hline$>80$ & $6.3(1)$ & $11.2(2)$ & $8.7(2)$ & $0.0(0)$ \\
\hline \multicolumn{5}{|l|}{ Highest education completed } \\
\hline High school or GED & $6.3(1)$ & $22.2(4)$ & $13.0(3)$ & $22.2(2)$ \\
\hline Vocational/ Technical & $0.0(0)$ & $0.0(0)$ & $4.4(1)$ & $11.1(1)$ \\
\hline College graduate & $37.5(6)$ & $27.8(5)$ & $39.1(9)$ & $44.4(4)$ \\
\hline Post-graduate or professional degree & $56.3(9)$ & $50.0(9)$ & $43.5(10)$ & $22.2(2)$ \\
\hline \multicolumn{5}{|l|}{ Color of skin unexposed to the sun } \\
\hline Reddish & $6.3(1)$ & $22.2(4)$ & $9.1(2)$ & $22.2(2)$ \\
\hline Very pale & $25.0(4)$ & $22.2(4)$ & $54.5(12)$ & $11.1(1)$ \\
\hline Pale with beige tint & $62.5(10)$ & $44.4(8)$ & $31.8(7)$ & $33.3(3)$ \\
\hline Light brown & $6.3(1)$ & $11.1(2)$ & $0.0(0)$ & $33.3(3)$ \\
\hline Dark brown & $0.0(0)$ & $0.0(0)$ & $4.5(1)$ & $0.0(0)$ \\
\hline \multicolumn{5}{|l|}{ First melanoma } \\
\hline Yes & $75.0(12)$ & $88.9(16)$ & $82.6(19)$ & $100.0(9)$ \\
\hline \multicolumn{5}{|c|}{ Skin self-exam during the 12 months prior to diagnosis? } \\
\hline No & $25.0(4)$ & $44.4(8)$ & $34.8(8)$ & $44.4(4)$ \\
\hline Yes, whole body exam & $25.0(4)$ & $16.7(3)$ & $13.0(3)$ & $11.1(1)$ \\
\hline Yes, partial exam & $50.0(8)$ & $38.9(7)$ & $52.2(12)$ & $44.4(4)$ \\
\hline \multicolumn{5}{|c|}{ Medical skin exam during the 12 months prior to diagnosis? } \\
\hline No & $37.5(6)$ & $38.9(7)$ & $34.8(8)$ & $77.8(7)$ \\
\hline Yes, whole body exam & $56.3(9)$ & $33.3(6)$ & $47.8(11)$ & $22.2(2)$ \\
\hline Yes, partial exam & $6.3(1)$ & $27.8(5)$ & $17.4(4)$ & $0.0(0)$ \\
\hline \multicolumn{5}{|l|}{ Who performed the medical skin exam } \\
\hline Dermatologist & $37.5(6)$ & $38.9(7)$ & $47.8(11)$ & $22.2(2)$ \\
\hline PCP or another HCP & $25.0(4)$ & $27.8(5)$ & $17.4(4)$ & $0.0(0)$ \\
\hline
\end{tabular}

$P C P$ primary care provider, $H C P$ health care provider

from "blueish dark" to "almost black", and the development of texture, e.g., "became puffy", "puffed up".

Thin NM patients reported elusive tactile sensations, such as "did not feel right, it was purely tactile" compared to more defined signs reported by thin SSM: "hardened, became more solid", and by thick NM: "felt like a hard pimple" or "felt like cracking a peanut open." Bleeding was characteristic of both thin $\mathrm{NM}$ and thick NM, with "blood spots under the mole" reported solely by thin NM while "bleeding after shaving or picking at the mole" was reported by both groups. Bleeding was not reported among the thin SSM group.

\section{Self-identified early signs of both nodular and superficial spreading melanoma}

Thin NM and thin SSM reported both symmetric e.g., "round", "circular", and asymmetric shape, e.g., "oblong", "like a kidney bean", "not perfectly round, jetted off"; border irregularity, e.g., "a little bit irregular", "jagged"; coloration in the pink-red-brown range, e.g., "pinkish", "reddish", "brownish", "reddish brown", "dark"; diameter ranging from "much smaller than a pencil eraser" to "[ .... the size of the little fingernail"; and small elevation, e.g., "tiny little bump", "elevated like a pimple". Both thin NM and thin SSM reported fast changes in diameter occurring over a few weeks period, and changes observed 
Table 2 Self-report survey variables crosstabulated by Melanoma type and depth

\begin{tabular}{|c|c|c|c|c|}
\hline \multirow[t]{2}{*}{ Variable, \% (n) } & \multicolumn{2}{|c|}{ Nodular Melanoma } & \multicolumn{2}{|c|}{ Superficial Spreading Melanoma } \\
\hline & $\leq 2 \mathrm{~mm}(n=16)$ & $>2 \mathrm{~mm}(n=18)$ & $\leq 2 \mathrm{~mm}(n=23)$ & $>2 \mathrm{~mm}(n=9)$ \\
\hline \multicolumn{5}{|c|}{ Physical signs in 12 months pre- diagnosis (checked all that apply ${ }^{a}$ ) } \\
\hline Itching & $12.5(2)$ & $22.2(4)$ & $17.4(4)$ & $44.4(4)$ \\
\hline Bleeding & $12.5(2)$ & $22.2(4)$ & $17.4(4)$ & $44.4(4)$ \\
\hline Irritation ${ }^{b}$ & $12.5(2)$ & $33.3(6)$ & $4.3(1)$ & $66.7(6)$ \\
\hline Tenderness $^{\mathrm{b}}$ & $0.0(0)$ & $38.9(7)$ & $4.3(1)$ & $55.6(5)$ \\
\hline Pain $^{\text {b }}$ & $6.3(1)$ & $33.3(6)$ & $4.3(1)$ & $55.6(5)$ \\
\hline Discharge & $0.0(0)$ & $5.6(1)$ & $4.3(1)$ & $11.1(1)$ \\
\hline Peeling & $0.0(0)$ & $33.3(6)$ & $4.3(1)$ & $11.1(1)$ \\
\hline \multicolumn{5}{|l|}{ Who discovered the melanoma? } \\
\hline Self or partner & $50.0(8)$ & $76.5(13)$ & $39.1(9)$ & $87.5(7)$ \\
\hline Friend or colleague & $0.0(0)$ & $11.8(2)$ & $8.7(2)$ & $0.0(0)$ \\
\hline Primary care physician & $12.5(2)$ & $0.0(0)$ & $13.0(3)$ & $0.0(0)$ \\
\hline Nurse or physician assistant & $0.0(0)$ & $0.0(0)$ & $4.3(1)$ & $0.0(0)$ \\
\hline Dermatologist & $31.3(5)$ & $5.9(1)$ & $26.1(6)$ & $0.0(0)$ \\
\hline Another professional & $6.3(1)$ & $5.9(1)$ & $8.7(2)$ & $12.5(1)$ \\
\hline \multicolumn{5}{|c|}{ Confidence differentiating healthy and problematic moles? } \\
\hline Not at all confident & $25(4)$ & $44.4(8)$ & $17.4(4)$ & $33.3(3)$ \\
\hline A little confident & $18.8(3)$ & $22.2(4)$ & $47.8(11)$ & $33.3(3)$ \\
\hline Somewhat confident & $18.8(3)$ & $11.1(2)$ & $13.0(3)$ & $22.2(2)$ \\
\hline Quite confident & $31.3(5)$ & $16.7(3)$ & $13.0(3)$ & $11.1(1)$ \\
\hline Extremely confident & $6.3(1)$ & $5.6(1)$ & $8.7(2)$ & $0.0(0)$ \\
\hline \multicolumn{5}{|c|}{ "I am someone who pays attention to my health" } \\
\hline Disagree & $0.0(0)$ & $5.6(1)$ & $0.0(0)$ & $22.2(2)$ \\
\hline Neither agree or disagree & $12.5(2)$ & $22.2(4)$ & $17.4(4)$ & $0.0(0)$ \\
\hline Agree & $31.3(5)$ & $50.0(9)$ & $39.1(9)$ & $33.3(3)$ \\
\hline Strongly agree & $56.3(9)$ & $22.2(4)$ & $43.5(10)$ & $44.4(4)$ \\
\hline
\end{tabular}

${ }^{a}$ The percentages do not add to $100 \%$ within each thickness group because the respondents were instructed to select all of the symptoms they had experienced from a list of possible symptoms

${ }^{b}$ We found statistically significant differences between the four thickness groups

over the course of six to 12 months in border irregularity, e.g., "got irregular", color darkening, e.g., from lighter to darker shades of brown, and the development of itchiness, e.g., "itchy", "really itchy".

\section{Discussion}

Early detection of the more rapidly-growing NM subtype is critical to improved patient outcomes. By the time a patient's NM shows ABCDE criteria, it is likely to be thicker at diagnosis and less curable. We employed qualitative methodology to facilitate recall of the patientidentified clinical features of problematic moles observed in advance of a formal melanoma diagnosis. This work has important implications for the early detection of $\mathrm{NM}$, which was previously thought to be undetectable at earlier stages.
Our study included 66 patients with NM and SSM, which is the largest and only second [38] qualitative study to date with this population. This study found several patient-identified early signs of melanoma that were unique to thin $\mathrm{NM}(\leq 2 \mathrm{~mm})$, including small white dot, visible blood spots underneath the mole, blue mole darkening fast, round mole becoming asymmetric fast, mole developing elevation fast, mole becoming puffy and crusty over time, and an overall physical sensation that the mole is different from other moles. Common criteria used for the early identification of melanoma, such as the ABCDE [18-20], elevated-firm-growing (EFG) $[21,22]$ or the blueblack (BB) rule [39] capture some of the early features of NM identified in our study; however, white coloration and very small diameter are not adequately represented in any of these mnemonics. 
Table 3 Perceived early signs and symptoms of Melanoma

\begin{tabular}{|c|c|c|}
\hline $\begin{array}{l}\text { Signs/ } \\
\text { symptoms }\end{array}$ & $\begin{array}{l}\text { Nodular melanoma } \\
\leq 2 \mathrm{~mm}\end{array}$ & $\begin{array}{l}\text { Superficial spreading melanoma } \\
\leq 2 \mathrm{~mm}\end{array}$ \\
\hline \multicolumn{3}{|l|}{ Asymmetry } \\
\hline Round & Round or roundish, circle or circular & Circular, like a big circle \\
\hline \multirow[t]{2}{*}{ Oblong } & Not perfectly round, oblong & Not perfectly round, jetted off \\
\hline & Like a small kidney bean & Not perfectly round, smaller in one direction \\
\hline Square & Square & \\
\hline \multicolumn{3}{|l|}{ Border } \\
\hline $\begin{array}{l}\text { Slightly } \\
\text { irregular }\end{array}$ & A little bit (or slightly) irregular & Half-moon edge on the side of the border \\
\hline \multirow[t]{2}{*}{ Jagged } & Jagged & Jagged border on one side \\
\hline & & Jagged, uneven, undefined, melted into skin \\
\hline \multirow{2}{*}{$\begin{array}{l}\text { Irregular } \\
\text { coloration }\end{array}$} & & Skin was a little bit pink, right on the border \\
\hline & & [Pinkish with] a tan border \\
\hline
\end{tabular}

\section{Color}

White Little white dot

Interior looked white or grey-white Brownish white

Darker white

Beige Very light beige $\mathrm{w}$ / black spot in the middle

Skin color shade

Blue Bluish dark

Bluish, multi-colored

Black Black freckle, like a black head Black dotted marks leaving a trail of brown

Pink Pinkish, looking like a pimple

Pinkish

Pink

Pinkish with a tan border

Pinkish, pearlescent- like a reflection of a pearl Pink bumpy/bubbly area with a black freckle on top

Nodular melanoma

$>2 \mathrm{~mm}$

Circular, like a big circle

Rectangular

A little irregular

Definite border, visible where it started and stopped

Dark pink

Red

Reddish

Reddish, almost bright red

Red, pinkish lesion

Tiny, little red spot

Brown

Brown

Brownish or maroonish

Brownish dark

Reddish Dark, reddish brown

brown

Really dark with an even darker spot inside

Dark

\section{Diameter}

Tiny dot

Like a dot made with a pen

Tiny, tiny little spots

Tiny, tiny, tiny, like the head of a pin

Like if you took a fine-tipped pen and you just put three dots on a piece of paper
Light and dark brown, with darker spots inside Brown

Brown

Brownish like a dark freckle

A little brownish

Dark brown

Brown and lighter/reddish

Brown with some red

Reddish brown

Dark, almost black

Brown with some purple

Dark
Tiny, like lead on a pencil, the size of a dot 
Table 3 Perceived early signs and symptoms of Melanoma (Continued)

\begin{tabular}{|c|c|c|c|}
\hline $\begin{array}{l}\text { Signs/ } \\
\text { symptoms }\end{array}$ & $\begin{array}{l}\text { Nodular melanoma } \\
\leq 2 \mathrm{~mm}\end{array}$ & $\begin{array}{l}\text { Superficial spreading melanoma } \\
\leq 2 \mathrm{~mm}\end{array}$ & $\begin{array}{l}\text { Nodular melanoma } \\
>2 \mathrm{~mm}\end{array}$ \\
\hline \multirow[t]{4}{*}{$\begin{array}{l}<\text { Pencil } \\
\text { eraser }\end{array}$} & Fairly small (1/8 of an inch) & Very small ( $2 \mathrm{~mm}$ to $3-4 \mathrm{~mm})$ & $\begin{array}{l}\text { Like a small pinhead used for sewing } \\
(1.5 \mathrm{~mm})\end{array}$ \\
\hline & Much smaller than a pencil eraser & Much smaller than a pencil eraser & Like the tip of a pen ( $2 \mathrm{~mm}$ ) \\
\hline & Like a half of a pencil eraser & Smaller than the size of a pencil eraser & \\
\hline & About $2 / 3$ of a pencil eraser & Half the size of a pencil eraser, very small & \\
\hline \multirow{3}{*}{$\begin{array}{l}\sim \text { Pencil } \\
\text { eraser }\end{array}$} & The size of a pencil eraser & Almost the size of a pencil eraser & The size of a pencil eraser \\
\hline & & The size of a pencil eraser or a little smaller & Like a big pimple ( $1 / 4$ of an inch \\
\hline & & & About $1 / 4$ in. round \\
\hline \multirow[t]{10}{*}{$\begin{array}{l}>\text { Pencil } \\
\text { eraser }\end{array}$} & A little bigger than a pencil eraser & Like two pencil-head erasers side-by-side & $\begin{array}{l}\text { A little bigger than the size of a } \\
\text { pencil eraser }\end{array}$ \\
\hline & The size of my little finger's fingernail & The size of the little fingernail on your hand & $\begin{array}{l}\text { As big as a very small blueberry, } \\
\text { maybe even smaller }\end{array}$ \\
\hline & Really tiny, smaller than $1 \mathrm{~cm}$ & $1 \mathrm{~cm}$ diameter & \\
\hline & & Smaller than the size of a dime & \\
\hline & & A little bit smaller than my thumbnail & The size of my thumbnail \\
\hline & & About the size of a dime, maybe bigger & About the size of a dime \\
\hline & & & The size of a penny \\
\hline & & & The size of a quarter, large \\
\hline & & & A little bigger than a quarter \\
\hline & & & Approximately $2 \mathrm{~cm}$ \\
\hline \multicolumn{4}{|l|}{ Elevation } \\
\hline \multirow[t]{8}{*}{ Slight } & Teeny little bump & A little raised (1/8 of an inch; 1 mm) & A little raised \\
\hline & Only slight [elevation] & Elevated a little, you could feel it, definitely & A little raised bump \\
\hline & Not huge, just slight [elevation] & Could feel it- if you ran your finger over it & A little bit raised but not grossly \\
\hline & Definitely more flat, but [also] raised a bit & Not very much elevated, a little bumpy & Elevated a little bit \\
\hline & Flat, less than $1 \mathrm{~mm}$, a really tiny thing & Like a little raised scar, bubbly a little bit & $\begin{array}{l}\text { A little bit elevated, some parts } \\
\text { higher than others }\end{array}$ \\
\hline & A little bit elevated but small, small & $\begin{array}{l}\text { Rounded at the top, a tiny bubble like a tiny } \\
\text { curve -also went down below the surface }\end{array}$ & $\begin{array}{l}\text { Could feel it, wasn't flush with the } \\
\text { skin ( } 1 / 4 \text { in. high) }\end{array}$ \\
\hline & Elevated above the skin like bumps on skin & & $\begin{array}{l}\text { The big the balloon was maybe } 1 / 8 \\
\text { of an inch }\end{array}$ \\
\hline & Elevated, like a pimple & & $\begin{array}{l}\text { Raised at least a } 1 / 4 \text { of an inch, maybe } \\
\text { more }\end{array}$ \\
\hline \multirow[t]{2}{*}{ Textured } & $\begin{array}{l}\text { A little bit raised, puffy, just like a little } \\
\text { bump }\end{array}$ & A little bit bumpy with a rough texture & $\begin{array}{l}\text { Growing out of the skin, I could feel } \\
\text { the crustiness }\end{array}$ \\
\hline & A little bit raised, puffed up & A little raised, a little crusty & $\begin{array}{l}\text { Felt like a bee sting, no pain (the } \\
\text { texture of it) }\end{array}$ \\
\hline \multirow[t]{2}{*}{ Prominent } & Raised up and prominent & & Raised, pronounced, thick (5 mm) \\
\hline & & & $\begin{array}{l}\text { Raised, like a swelling from a bee } \\
\text { sting }\end{array}$ \\
\hline \multicolumn{4}{|c|}{ Evolution [chronology] } \\
\hline \multirow[t]{2}{*}{$\begin{array}{l}\text { Asymmetry } \\
\text { change }\end{array}$} & From round to oblong [2 weeks] & Changed shape [In a matter of weeks] & $\begin{array}{l}\text { Looked different from last time I } \\
\text { checked [ } 2 \text { months] }\end{array}$ \\
\hline & & Not the same shape as in the past [ 6 months] & \\
\hline \multirow{2}{*}{$\begin{array}{l}\text { Border } \\
\text { change }\end{array}$} & Became more irregular [6-12 months] & Got irregular [In a matter of weeks] & \\
\hline & & $\begin{array}{l}\text { Some parts of the border became red [Over } \\
\text { the last few years] }\end{array}$ & \\
\hline
\end{tabular}


Table 3 Perceived early signs and symptoms of Melanoma (Continued)

\begin{tabular}{|c|c|c|c|}
\hline $\begin{array}{l}\text { Signs/ } \\
\text { symptoms }\end{array}$ & $\begin{array}{l}\text { Nodular melanoma } \\
\leq 2 \mathrm{~mm}\end{array}$ & $\begin{array}{l}\text { Superficial spreading melanoma } \\
\leq 2 \mathrm{~mm}\end{array}$ & $\begin{array}{l}\text { Nodular melanoma } \\
>2 \mathrm{~mm}\end{array}$ \\
\hline \multirow[t]{7}{*}{$\begin{array}{l}\text { Color } \\
\text { change }\end{array}$} & $\begin{array}{l}\text { From light beige to beige with a black spot } \\
\text { [Over time] }\end{array}$ & Became darker at the center & \\
\hline & $\begin{array}{l}\text { From brownish to darker with brown tinges } \\
\text { [2 weeks] }\end{array}$ & From light brown to really dark [Really fast] & \\
\hline & & $\begin{array}{l}\text { Got darker, from light to dark brown [6 } \\
\text { months] }\end{array}$ & \\
\hline & Became a little bit dark & Got a little darker [Slowly, over the years] & \\
\hline & & & $\begin{array}{l}\text { From brown to brown with purple in } \\
\text { it [2-4 months] }\end{array}$ \\
\hline & $\begin{array}{l}\text { From brown to black, in a dripping pattern } \\
\text { [2 weeks] }\end{array}$ & & From brown to black [4-5 months] \\
\hline & From bluish dark to almost black [3 months] & & Blackened \\
\hline \multirow{6}{*}{$\begin{array}{l}\text { Diameter } \\
\text { change }\end{array}$} & Didn't get too much bigger [2 weeks] & Grew in size [Overnight] & Got bigger, from 0.5 to $2 \mathrm{~cm}$ [4 weeks] \\
\hline & Grew quickly, all of a sudden [4-6 weeks] & Got a little bigger [Over the last few years] & Got bigger [3-4 months] \\
\hline & Got a little bit bigger, larger [3 months] & Grew a little bit bigger [Slowly, over the years] & $\begin{array}{l}\text { Came back/grew after biopsy [4-5 } \\
\text { months] }\end{array}$ \\
\hline & Got bigger, from 1 to $2 \mathrm{~mm}$ [6-12 months] & $\begin{array}{l}\text { Grew in size, from nothing to pencil eraser size } \\
\text { [In a matter of weeks] }\end{array}$ & Got slightly bigger [Almost 1 year] \\
\hline & Got (a little bit) bigger [Over time] & & Kept getting bigger and bigger \\
\hline & Growing in size [12 months] & & \\
\hline \multirow{6}{*}{$\begin{array}{l}\text { Elevation } \\
\text { change }\end{array}$} & Got raised [2 weeks] & & Got higher [4 weeks] \\
\hline & & & More raised [2 months] \\
\hline & & Got more density to it [Very quick] & Became thicker [3.5 weeks] \\
\hline & Became more pronounced & & $\begin{array}{l}\text { Became more pronounced, } \\
\text { protruding from the skin [Relatively } \\
\text { quickly] }\end{array}$ \\
\hline & Became puffy [6-12 months] & & $\begin{array}{l}\text { Became bumpier, not smooth [2-4 } \\
\text { months] }\end{array}$ \\
\hline & Puffed up [Over time] & & \\
\hline \multicolumn{4}{|c|}{ Physical signs and symptoms } \\
\hline \multirow[t]{3}{*}{ Itchy } & A little bit itchy & & \\
\hline & Really itchy & Itching a good deal & \\
\hline & Became itchy & Became itchy [6 months] & Became itchy [2 months] \\
\hline \multirow[t]{2}{*}{ Bleeding } & Bleeding after shaving/ picking at it & & $\begin{array}{l}\text { Bleeding after shaving or squeezing } \\
\text { [2-3 weeks] }\end{array}$ \\
\hline & Blood spots under the mole & & Bleeding \\
\hline \multirow[t]{3}{*}{ Weeping } & & & Weeping pus \\
\hline & & & Discharge \\
\hline & & & Moist \\
\hline \multirow[t]{6}{*}{$\begin{array}{l}\text { Multiple } \\
\text { signs }\end{array}$} & A little bit itchy and bleeding [Once] & Itchy, scaling and flaky, cracking, bleeding & $\begin{array}{l}\text { Itchy, sore/sensitive, and bleeding- } \\
\text { from towel drying }\end{array}$ \\
\hline & & & $\begin{array}{l}\text { Bleeding a little, open sore, scabbed } \\
\text { over }\end{array}$ \\
\hline & & A little bit itchy and a little bit scaly & Itchy and erupting [Periodically] \\
\hline & & Itchy, did not heal, looked like a keloid scar & \\
\hline & & Became dry, scaly, peeling [All of the sudden] & \\
\hline & & $\begin{array}{l}\text { Sensitive and hurting/ sore, radiating pain [All } \\
\text { of a sudden] }\end{array}$ & Itchy and painful \\
\hline
\end{tabular}


Table 3 Perceived early signs and symptoms of Melanoma (Continued)

\begin{tabular}{|c|c|c|c|}
\hline $\begin{array}{l}\text { Signs/ } \\
\text { symptoms }\end{array}$ & $\begin{array}{l}\text { Nodular melanoma } \\
\leq 2 \mathrm{~mm}\end{array}$ & $\begin{array}{l}\text { Superficial spreading melanoma } \\
\leq 2 \mathrm{~mm}\end{array}$ & $\begin{array}{l}\text { Nodular melanoma } \\
>2 \mathrm{~mm}\end{array}$ \\
\hline & & & $\begin{array}{l}\text { Oozing- from towel drying, sensitive, } \\
\text { breaking open }\end{array}$ \\
\hline \multirow{4}{*}{$\begin{array}{l}\text { Tactile } \\
\text { sensations }\end{array}$} & Did not feel right, it was purely tactile & & Could feel it- by touching \\
\hline & & $\begin{array}{l}\text { Hardened, became more solid [Over a few } \\
\text { days] }\end{array}$ & Hardened a little bit \\
\hline & & & Felt like a hard pimple- by touching \\
\hline & & & $\begin{array}{l}\text { Felt like cracking a peanut open- after } \\
\text { squeezing }\end{array}$ \\
\hline
\end{tabular}

Additionally, this study found some overlap between the patient-identified early signs of NM and SSM, including round and asymmetric shape, red or brown mole, raised pink bump, darkening of the mole, border becoming irregular, and itchiness developed over time. Symmetric round shape, small diameter $(<6 \mathrm{~mm})$, and itchiness are not captured in the ABCDE criteria; however, elevation or vertical growth are included in the EFG mnemonic, which is typically used to identify NM and less commonly used for the early identification of SSM. A 2003 brief by Kelly and colleagues [21] noted higher percentage of symmetric nodular melanomas $(90 \%)$ and regular borders and single coloration (78\%)compared to superficial spreading melanoma- and the appearance of a round nodule growing vertically from the onset.

While smaller size diameter and changes in shape, border, color, diameter, elevation and itchiness have been previously reported as features of NM [38, 40-42], this is the first study to provide patient-reported chronology for observed changes in mole features. Specifically, among early NMs, changes in mole shape, darkening of color, and rapid vertical growth reportedly occurred over a 2 week period, accompanied by tactile sensations suggestive of "something different and potentially problematic" about the mole.

\section{Limitations}

Given this study asked retrospectively about the early signs of melanoma, there may be a concern about the accuracy of patient recall given the interval between the onset of signs/symptoms and the patient interviews. Prior results from a large nested case-control study investigating the impact of recall bias on effect estimates for various self-reported melanoma risk factors suggested some evidence of bias, with the overall conclusion that the length of time between diagnosis and interview did not systematically affect recall [43]. In a qualitative study asking about retrospective memories, it is virtually impossible to gauge the impact of recall bias. In our study, time from diagnosis to the interview did not differ substantially across the three groups included in the qualitative analysis, thin NM, thin SSM, thick NM, which suggests the accuracy of self-reported data might be comparable across the groups. Notably, results from our written survey show that 5 patients with thin NM (5/16, 31\%) reported clinical signs and symptoms. Findings from interview data show that 8 patients with thin NM (50\%) reported clinical signs and symptoms: bleeding alone $(n=3)$, itching alone $(n=2)$, itching and bleeding $(n=2)$, and an undefined tactile sensation accompanied by the appraisal that "did not feel right" about the mole $(n=1)$. The discrepancy between the two data sources could be explained by extensive prompts employed by the interviewer to facilitate recall and speak to the relevancy of our qualitative methodology to provide meaningful and personalized information. Last, patients' awareness of individual risk factors (e.g., personal or family history; phenotypic features) could affect people's perceptions of the disease, including readiness to examine the skin for the early signs of skin cancer. In this study, we did not examine patients' knowledge of risk factors.

\section{Future directions for research}

Results from our formative study can guide the development of quantitative measures to assess early detection of nodular and superficial spreading melanoma, which would allow for further quantification of rates of selfidentified early features of melanoma. Our results could also guide future research to develop educational materials about the early detection of various types of melanoma, including the NM subtype, which appears to be more amenable to earlier detection by patients than previously claimed. Further validation of our findings may then warrant revision of existing criteria for earlier clinical recognition of the NM subtype.

\section{Conclusions}

Overall, our findings indicate that some of the patientidentified early signs of thin nodular melanoma are not currently ascribed to any of the existing mnemonics 
used for the early identification of melanoma (ABCDE, EFG, $B B$ rule). These specific features from our findings include the appearance of a small persistent bump or pink pimple, or a tiny round nodule of white, blue, or black color, which feels itchy and undergoes rapid changes in appearance, and "feels" noticeable over a brief 2 weeks. Incorporation of These findings could inform future development of educational materials on the early detection of melanoma, especially as it pertains to the key warning signs of nodular melanoma. Nodular melanoma is a less common but more fatal melanoma subtype, that has typically eluded early detection strategies and occurs more frequently in older white men $[44,45]$ and across various racial-ethnic groups, such as Hispanic whites $[9,46]$. Individuals at high risk as well as healthcare professionals involved in their care particularly benefit from learning about these early signs of nodular melanoma amenable to self-identification.

\section{Supplementary Information}

The online version contains supplementary material available at https://doi. org/10.1186/s12885-021-08072-4.

Additional file 1: Appendix A: Table S1. Clinical Features of Nodular Melanoma (NM) and Superficial Spreading Melanoma (SSM), as per Previously Published Reports. Appendix B. Interview Guide.

Additional file 2. Standards for Reporting Qualitative Research (SRQR) Checklist.

\section{Acknowledgements}

Not applicable.

\section{Authors' contributions}

Conceptualization: AC, SS, AG; Data curation: AC, CM, JD; Formal analysis: AC, CM, CB, KB, AG; Investigation: AC, SS, AG; Methodology: AC, SS, AG; Project Administration: AC, CM, JD; Resources: AK, HT, AG; Supervision: SS, AG; Visualization: AC, CM; Writing-Original Draft: AC; Writing: AC, CM, SS, AG. All co-authors read and approved the final draft of the manuscript.

\section{Funding}

This study did not receive any funding. AC is supported by postdoctoral research fellowships from the Canadian Institutes of Health Research (CIHR) and Fonds de Recherche du Quebec - Santé (FRQS). CM is supported by a Vanier Canada Scholarship, an Alberta Innovates Graduate Studentship in Health Innovation and a University of Calgary Training in Research and Clinical Trials in Integrative Oncology (TRACTION) fellowship. KB is supported by a Vanier Canada Scholarship. CB is supported by a doctoral award from $\mathrm{CIHR}$. HT is supported by a K24 grant from the National Institute of Health (NIH) /National Cancer Institute (NCI) (2K24CA149202).

\section{Availability of data and materials}

The datasets used and/or analysed during the current study available from the corresponding author on reasonable request.

\section{Declarations}

\section{Ethics approval and consent to participate}

The study was approved by the Institutional Research Board (IRB) of Harvard T.H. Chan School of Public Health and the Research Ethics Board (REB) of McGill University, which are in agreement with the Declaration of Helsinki. All participants provided written informed consent prior to enrollment in the study.
Consent for publication

Not applicable.

\section{Competing interests}

The authors declare that they have no competing interests.

\section{Author details}

${ }^{1}$ Department of Social and Behavioral Sciences, Harvard T.H. Chan School of Public Health, 401 Park Drive, West Wing 4th floor, 403G, Boston, MA 02215, USA. ${ }^{2}$ Department of Psychology, University of Calgary, Calgary, Canada. ${ }^{3}$ Department of Educational and Counselling Psychology, McGill University, Montreal, Canada. ${ }^{4}$ Harvard Medical School, Boston, USA. ${ }^{5}$ Department of Dermatology, Massachusetts General Hospital, Boston, USA. ${ }^{6}$ Department of Dermatology, Pigmented Lesion and Melanoma Program, Stanford University Medical Center, Stanford, USA. ${ }^{7}$ Dermatology Service, Veterans Affairs Palo Alto Health Care System, Palo Alto, USA.

Received: 19 February 2021 Accepted: 18 March 2021

Published online: 07 April 2021

\section{References}

1. Little $E G$, Eide MJ. Update on the current state of melanoma incidence. Dermatol Clin. 2012;30(3):355-61. https://doi.org/10.1016/j.det.2012.04.001.

2. Tripp MK, Watson M, Balk SJ, Swetter SM, Gershenwald JE. State of the science on prevention and screening to reduce melanoma incidence and mortality: the time is now. CA Cancer J Clin. 2016;66(6):460-80. https://doi. org/10.3322/caac.21352.

3. Thrift AP, Gudenkauf FJ. Melanoma incidence among non-hispanic whites in all 50 US States from 2001 through 2015. J Natl Cancer Inst. 2019;112: 533-9.

4. Greenwald HS, Friedman EB, Osman I. Superficial spreading and nodular melanoma are distinct biological entities: a challenge to the linear progression model. Melanoma Res. 2012;22(1):1-8. https://doi.org/10.1097/ CMR.0b013e32834e6aa0.

5. Elder DE, Massi D, Scolyer R, Willemze R. WHO Classification of Skin Tumours, vol. 11. 4th ed; 2018.

6. Baade PD, English DR, Youl PH, McPherson M, Elwood JM, Aitken JF. The relationship between melanoma thickness and time to diagnosis in a large population-based study. Arch Dermatol. 2006;142(11):1422-7. https://doi. org/10.1001/archderm.142.11.1422.

7. Balch CM, Soong S-J, Gershenwald JE, Thompson JF, Reintgen DS, Cascinelli $\mathrm{N}$, et al. Prognostic factors analysis of 17,600 melanoma patients: validation of the American joint committee on Cancer melanoma staging system. J Clin Oncol. 2001;19(16):3622-34. https://doi.org/10.1200/JCO.2001.19.16.3 622.

8. Balch CM, Gershenwald JE, Soong S, Thompson JF, Atkins MB, Byrd DR, et al. Final version of 2009 AJCC melanoma staging and classification. J Clin Oncol. 2009;27(36):6199-206. https://doi.org/10.1200/JCO.2009.23.4799.

9. Demierre M-F, Chung C, Miller DR, Geller AC. Early detection of thick melanomas in the united states: beware of the nodular subtype. Arch Dermatol. 2005;141(6). https://doi.org/10.1001/archderm.141.6.745.

10. Mar V, Roberts H, Wolfe R, English DR, Kelly JW. Nodular melanoma: a distinct clinical entity and the largest contributor to melanoma deaths in Victoria, Australia. J Am Acad Dermatol. 2013;68(4):568-75. https://doi.org/1 0.1016/j.jaad.2012.09.047

11. Dessinioti C, Dimou N, Geller AC, Stergiopoulou A, Lo S, Keim U, et al. Distinct Clinicopathological and prognostic features of thin nodular primary melanomas: an international study from 17 centers. J Natl Cancer Inst. 2019; 111(12):1314-22. https://doi.org/10.1093/jnci/djz034.

12. Green AC, Baade P, Coory M, Aitken JF, Smithers M. Population-based 20year survival among people diagnosed with thin melanomas in Queensland, Australia. J Clin Oncol. 2012;30(13):1462-7. https://doi.org/10.12 00/JCO.2011.38.8561

13. Green AC, Viros A, Hughes MCB, et al. Nodular Melanoma: A Histopathologic Entity? Acta Derm Venereol 2018;98:460-462. doi:i https:// doi.org/10.2340/00015555-2855

14. Haenssle HA, Hoffmann S, Buhl T, Emmert S, Schön MP, Bertsch HP, et al. Assessment of melanoma histotypes and associated patient related factors: basis for a predictive statistical model. J Dtsch Dermatol Ges. 2015;13(1):3744. https://doi.org/10.1111/ddg.12561. 
15. Swetter SM, Pollitt RA, Johnson TM, Brooks DR, Geller AC. Behavioral determinants of successful early melanoma detection: role of self and physician skin examination. Cancer. 2012;118(15):3725-34. https://doi.org/1 $0.1002 /$ cncr.26707

16. Cicchiello M, Lin MJ, Pan Y, McLean C, Kelly JW. An assessment of clinical pathways and missed opportunities for the diagnosis of nodular melanoma versus superficial spreading melanoma: pathways for diagnosis of NM versus SSM. Austr J Dermatol. 2016;57(2):97-101. https://doi.org/10.1111/a jd.12416.

17. Moreau JF, Weinstock MA, Geller AC, Winger DG, Ferris LK. Individual and ecological factors associated with early detection of nodular melanoma in the United States. Melanoma Res. 2014;24(2):165-71. https://doi.org/10.1 097/CMR.0000000000000049.

18. Abbasi NR, Shaw HM, Rigel DS, Friedman RJ, McCarthy WH, Osman I, et al. Early diagnosis of cutaneous melanoma: revisiting the ABCD criteria. JAMA 2004;292(22):2771-6. https://doi.org/10.1001/jama.292.22.2771.

19. Friedman RJ, Rigel DS, Kopf AW. Early detection of malignant melanoma: the role of physician examination and self-examination of the skin. CA Cancer J Clin. 1985;35(3):130-51. https://doi.org/10.3322/canjclin.35.3.130.

20. Rigel DS, Russak J, Friedman R. The evolution of melanoma diagnosis: 25 years beyond the ABCDs. CA Cancer J Clin. 2010;60(5):301-16. https://doi. org/10.3322/caac.20074.

21. Kelly JW, Chamberlain AJ, Hospital A, Staples MP, McAvoy B. No longer as simple as ABC. Aust Fam Physician. 2003;32(9):706-9.

22. Chamberlain A, Ng J. Cutaneous melanoma: atypical variants and presentations. Aust Fam Physician. 2009;38(7):476-82.

23. Warycha MA, Christos PJ, Mazumdar M, Darvishian F, Shapiro RL, Berman RS, et al. Changes in the presentation of nodular and superficial spreading melanomas over 35 years. Cancer. 2008;113(12):3341-8. https://doi.org/10.1 002/cncr.23955.

24. Carli P, Giorgi VD, Palli D, et al. Self-detected cutaneous melanomas in Italian patients. Clin Exp Dermatol. 2004;29(6):593-6. https://doi.org/10.1111/ j.1365-2230.2004.01628.x.

25. Carli P, De Giorgi V, Palli D, et al. Patterns of detection of superficial spreading and nodular-type melanoma: a multicenter Italian study. Dermatol Surg. 2004;30(11):1371-6.

26. De Giorgi V, Grazzini M, Rossari S, et al. Is skin self-examination for cutaneous melanoma detection still adequate? A retrospective study. Dermatology. 2012;225(1):31-6. https://doi.org/10.1159/000339774.

27. Britten N. Qualitative Interviews. In: Qualitative Research in Health Care: Wiley; 2007. p. 12-20. https://doi.org/10.1002/9780470750841.ch2.

28. Coups EJ, Geller AC, Weinstock MA, Heckman CJ, Manne SL. Prevalence and correlates of skin Cancer screening among middle-aged and older white adults in the United States. Am J Med. 2010;123(5):439-45. https://doi.org/1 0.1016/j.amjmed.2009.10.014

29. Fischer AH, Wang TS, Yenokyan G, Kang S, Chien AL. Association of Indoor Tanning Frequency with Risky sun Protection Practices and Skin Cancer Screening. JAMA Dermatol. 2017;153(2):168-74. https://doi.org/10.1001/jama dermatol.2016.3754.

30. Geller AC, Emmons K, Brooks DR, Zhang Z, Powers C, Koh HK, et al. Skin cancer prevention and detection practices among siblings of patients with melanoma. J Am Acad Dermatol. 2003;49(4):631-8. https://doi.org/10.1067/ S0190-9622(03)02126-1.

31. Geller AC, Keske RR, Haneuse S, et al. Skin cancer early detection practices among adult survivors of childhood cancer treated with radiation. J Invest Dermatol. 2019;139(9):1898-1905.e2. https://doi.org/10.1016/j.jid.2019.02.033.

32. Vogel Rl, Strayer LG, Engelman L, Nelson HH, Blaes AH, Anderson KE, et al. Sun exposure and protection behaviors among long-term melanoma survivors and population controls. Cancer Epidemiol Prev Biomark. 2017; 26(4):607-13. https://doi.org/10.1158/1055-9965.EPI-16-0854.

33. Kvale $S$, Brinkmann S. Interviews: learning the craft of qualitative research interviews. 2nd ed. Los Angeles: Sage Publications, Inc.; 2009.

34. O'Brien BC, Harris IB, Beckman TJ, Reed DA, Cook DA. Standards for reporting qualitative research: a synthesis of recommendations. Acad Med. 2014;89(9):1245-51. https://doi.org/10.1097/ACM.0000000000000388.

35. Dedoose Version 8.0.35. SocioCultural Research Consultants, LLC www. dedoose.com

36. Braun V, Clarke V. Using thematic analysis in psychology. Qual Res Psychol. 2006;3(2):77-101. https://doi.org/10.1191/1478088706qp063oa.

37. Lincoln YS, Guba EG. Naturalistic inquiry. Newbury Park: Sage Publications, Inc.; 1985.
38. Bergenmar M, Hansson J, Brandberg Y. Detection of nodular and superficial spreading melanoma with tumour thickness $12.0 \mathrm{~mm}$ - an interview study. Eur J Cancer Prev. 2002;11(1):49-55. https://doi.org/10.1097/00008469-2002 02000-00007.

39. Argenziano G, Longo C, Cameron A, Cavicchini S, Gourhant JY, Lallas A, et al. Blue-black rule: a simple dermoscopic clue to recognize pigmented nodular melanoma. Br J Dermatol. 2011;165(6):1251-5. https://doi.org/1 0.1111/j.1365-2133.2011.10621.x.

40. Bono A, Tolomio E, Carbone A, Moglia D, Crippa F, Tomatis S, et al. Small nodular melanoma: the beginning of a life-threatening lesion. A clinical study on 11 cases. Tumori J. 2011;97(1):35-8. https://doi.org/10.1177/03 0089161109700107.

41. Kalkhoran S, Milne O, Zalaudek I, et al. Historical, clinical, and dermoscopic characteristics of thin nodular melanoma. Arch Dermatol. 2010;146(3). https://doi.org/10.1001/archdermatol.2009.369.

42. Chamberlain AJ, Fritschi L, Kelly JW. Nodular melanoma: patients' perceptions of presenting features and implications for earlier detection. J Am Acad Dermatol. 2003;48(5):694-701. https://doi.org/10.1067/mjd.2003.21 6.

43. Parr CL, Hjartåker A, Laake $P$, Lund E, Veierød MB. Recall Bias in melanoma risk factors and measurement error effects: a nested case-control study within the Norwegian women and Cancer study. Am J Epidemiol. 2009; 169(3):257-66. https://doi.org/10.1093/aje/kwn363.

44. Geller AC, Elwood M, Swetter SM, Brooks DR, Aitken J, Youl PH, et al. Factors related to the presentation of thin and thick nodular melanoma from a population-based cancer registry in Queensland Australia. Cancer. 2009; 115(6):1318-27. https://doi.org/10.1002/cncr.24162.

45. Chamberlain AJ, Fritschi L, Giles GG, Dowling JP, Kelly JW. Nodular type and older age as the most significant associations of thick melanoma in victoria, australia. Arch Dermatol. 2002;138(5). https://doi.org/10.1001/archderm.138.5 609.

46. Pollitt RA, Clarke CA, Swetter SM, Peng DH, Zadnick J, Cockburn M. The expanding melanoma burden in California hispanics: importance of socioeconomic distribution, histologic subtype, and anatomic location. Cancer. 2011;117(1):152-61. https://doi.org/10.1002/cncr.25355.

\section{Publisher's Note}

Springer Nature remains neutral with regard to jurisdictional claims in published maps and institutional affiliations.

Ready to submit your research? Choose BMC and benefit from:

- fast, convenient online submission

- thorough peer review by experienced researchers in your field

- rapid publication on acceptance

- support for research data, including large and complex data types

- gold Open Access which fosters wider collaboration and increased citations

- maximum visibility for your research: over $100 \mathrm{M}$ website views per year

At BMC, research is always in progress.

Learn more biomedcentral.com/submissions 